\title{
Uncertainty in measurements of power and energy on power networks
}

\author{
E. Manov, N. Kolev \\ Department of Measurement and Instrumentation, \\ Technical University - Sofia, \\ bul. "Kliment Ohridski" No8, bl.2, 1000 Sofia, Bulgaria \\ Tel./fax: (+ 359 2) 96524 47, 965 23 82, e-mail: manov@vmei.acad.bg \\ n_kolev@vmei.acad.bg
}

\begin{abstract}
The problem on measurement of power and energy in single-phase and three-phase networks is always very important. The accuracy and precision of measurement is of equal importance for both manufacturers and consumers. The general problem is to determine the uncertainty of the energy produced in a specified power station and delivered to different consumers. Measuring instruments used for energy measurement are voltage and current instrument transformers and electricity meters. The approach proposed combines the information that can be derived from the nominal accuracy specifications of the instrument transformers with the information resulting from the calibration of the electricity meters. The combination allows achieving the evaluation of uncertainty in power and energy measurement. Both instrument transformers are subject to ratio error and phase error. In the paper an expression for maximum (positive and negative) errors as a function of the relative load current is derived. A method for calibration of electricity meters, measurement instruments used in the procedure, processing and presentation of the final results are presented as well. Having the information about the accuracy of both voltage and current instrument transformers and finding the uncertainty of electricity meter (according to the method outlined), it is possible to determine the total uncertainty of energy (power) measurement in conditions of load current variations and different modes of operation. The final accuracy of energy measurement may be presented by giving the specification limits in terms of measured value.
\end{abstract}

\section{Key words}

measurement, power, network, uncertainty, procedure.

\section{Introduction}

The problem on measurement of power and energy in mono-phase and three-phase networks is always very important. The accuracy and precision of measurement is of equal importance for both manufacturers and consumers, taking into account world globalization and increasing market demand and exchange of electrical energy. It should be mentioned that considering the great number of publications in the field of power measurement it is difficult to realize significant contribution to the above problem. On the other hand every scientific research leading to the improvement of metrology characteristics and features of power and energy measurement systems is valuable and. with practical application. Currently the large number of the power and energy measuring devices are sophisticated computer-based systems using digital conversion of input current and voltage and having various features for measurement, calculation and visualization of different parameters.

\section{Statement of the problem}

In the paper the general problem is to determine the uncertainty of the energy produced in a specified power station and delivered to different consumers. This problem is very important now for Bulgaria because the energy home trade within country has been recently introduced. The electrical energy area includes the generation of energy, the distribution of energy and finally the utilization of energy. It is clear that the generated energy should be measured before distribution for each one of the power station outputs. Measuring instruments used for energy measurement usually are:

- Voltage and current instrument transformers;

- $\quad$ Electricity meters

The above mentioned instruments should be with compatible characteristics.

\section{Uncertainty Analysis}

\section{A. Voltage and current instrument transformers}

It is well known that both instrument transformers are subject to ratio error and phase error. These errors are set by National and International Standards and are outlined into the transformer documentation. Both ratio errors and phase errors are very important when voltage and current instrument transformers are used to extend the range of watt meters and electricity meters (watt-hour meters).

The voltage ratio error $\left(f_{u}\right)$ of the voltage instrument transformer is a result of the difference between nominal and real transformation coefficient. Phase error $\left(\delta_{\mathrm{u}}\right)$ is defined by the phase angle difference between the vectors of the primary and secondary voltage. The difference is zero when transformer is ideal. Both ratio and phase errors depend on:

- Burden values;

- Power factor;

- Range of the input voltage deviation;

The current ratio error $\left(f_{i}\right)$ of the current instrument transformer is a result of the difference between nominal 
and real transformation coefficient. Phase error $\left(\delta_{i}\right)$ is defined by the phase angle difference between the vectors of the primary and secondary current. The difference is zero when transformer is ideal. Both ratio and phase errors depend on:

- Burden values;

- Power factor;

- Range of the primary current variation;

Maximum positive error $\mathrm{f}_{\mathrm{p}+}$ for power measurement using both voltage and current instrument transformers is defined by the formula:

$$
\mathrm{f}_{\mathrm{p}+}=\frac{\left(1+\mathrm{f}_{\mathrm{u}}\right)\left(1+\mathrm{f}_{\mathrm{i}}\right) \cos \left(\phi-\delta_{\mathrm{u}}-\delta_{\mathrm{i}}\right)}{\cos \phi}-1
$$

Maximum negative error fp- for the above mentioned case is:

$$
\mathrm{f}_{\mathrm{p}-}=\frac{\left(1-\mathrm{f}_{\mathrm{u}}\right)\left(1-\mathrm{f}_{\mathrm{i}}\right) \cos \left(\phi+\delta_{\mathrm{u}}+\delta_{\mathrm{i}}\right)}{\cos \phi}-1
$$

Where: $f_{u} \& f_{i}$ are ratio errors of the voltage and current instrument transformers;

$\delta_{\mathrm{u}} \& \delta_{\mathrm{i}}$ are phase errors of the voltage and current instrument transformers;

$\cos \phi$ - power factor of the burden;

All errors are taken with a positive sign.

Both expressions define an area where the real error due to instrument transformers in power measurement is situated.

The graphical presentation of this area as a function of the relative load current is shown in Fig.1. For practical applications when the information about transformers is available (graphics for both ratio and phase error) these errors can be determined and considered as systematic.

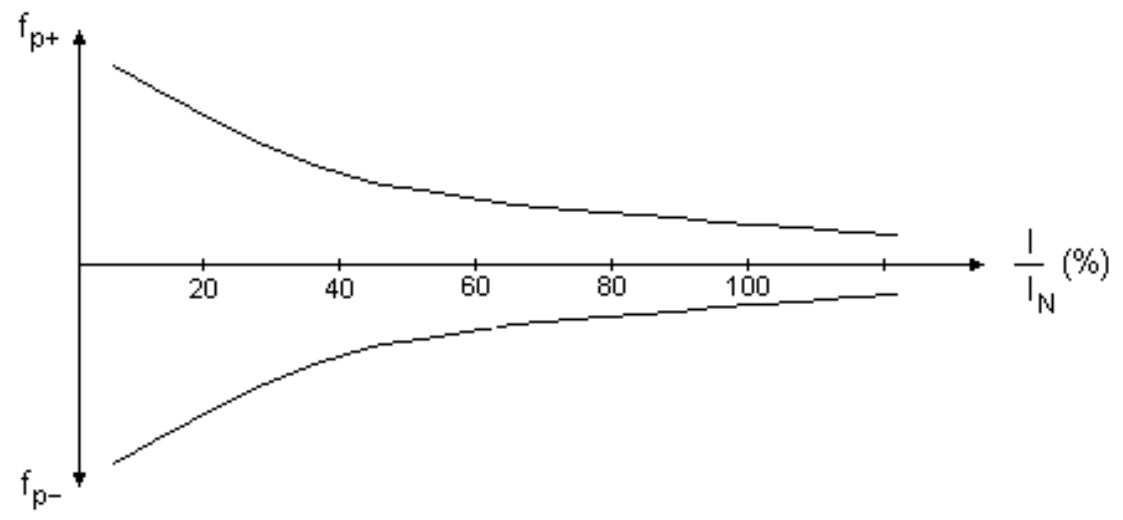

Fig.1. Error presentation

\section{B. Calibration of single-phase and three-phase electricity meters}

The following method defines the principle of calibration, measurement instruments used in the procedure, processing and presentation of the final results.

\section{1) The principle of calibration}

The calibration is based on direct comparison between measured energy values for both standard and electricity meter.

The relative error $\varepsilon$ is given by the formula:

$$
\varepsilon=\frac{\mathrm{N}_{\mathrm{c}}-\mathrm{N}_{\mathrm{r}}}{\mathrm{N}_{\mathrm{r}}} 100,[\%]
$$

where: $\mathrm{N}_{\mathrm{c}}=\mathrm{T} . \mathrm{C}_{\mathrm{pz}}$

$\mathrm{T}$ - base time (time of measurement), in sec.

$\mathrm{C}_{\mathrm{pz}}$ - frequency of the standard for $100 \% \mathrm{P}(\mathrm{Q})$,

in $\mathrm{p} / \mathrm{s}$

( $\mathrm{P}$ - active power; $\mathrm{Q}$ - reactive power);

energy;

\section{2) Measuring instrument (standard)}

The standard used in calibration is a 3-Phase Precision Measuring Instrument TPZ 303. The following parameters are measured, calculated and displayed to provide a comprehensive analysis of a three phase system showing instantaneous and integrated values:

- True RMS values for each voltage and current input;

- Analysis of DC component and harmonic content;

- Phase angles between all voltages and currents;

- Active, reactive and apparent power;

- Power factor for each phase;

- Total active, reactive and apparent power;

- Phase rotation sequence and frequency.

It is possible to input external current and voltage transformers ratios, measured parameters will then be shown as primary values.

\section{3) Processing of the results in calibration}

The matematical model describing the relation between output value $\Delta$ (percentage error) and input values $\Delta \mathrm{i}$ is:

$$
\Delta=\Delta_{1}-\Delta_{2}+\Delta_{\mathrm{pc}}
$$


The estimate of the measured value $\Delta$, denoted by $\delta$ results from equation (4) after substituting the estimates of all input values:

$$
\delta=\delta_{1}-\delta_{2}+\delta_{\mathrm{pc}}
$$

where: $\delta$ - estimate of the electricity meter error;

$\delta_{1}$ - estimate of the measured electricity meter error;

$\delta_{2}$ - estimate of the standard error, presented in the calibration certificate;

$\delta_{\mathrm{pc}}-$ correction for the resolution of the standard display;

All values are in percents.

The estimate of measured electricity meter error $\delta_{1}$ is obtained by calculating the arithmetic mean of a set of $n$ measurement results:

$$
\delta_{1}=\frac{1}{\mathrm{n}} \sum_{\lambda=1}^{\mathrm{n}} \varepsilon_{\lambda}
$$

where : $\varepsilon_{\lambda}-$ value of the error for $\lambda$ result in the calibration point,

$\mathrm{n}$ - number of the measurement results in the calibration point

Standard uncertainty $\mathrm{u}\left(\delta_{1}\right)$ is determined by the standard deviation of the estimated error value according to the expression:

$$
u\left(\delta_{1}\right)=\sqrt{\frac{1}{\mathrm{n}(\mathrm{n}-1)} \sum_{\lambda=1}^{\mathrm{n}}\left(\varepsilon_{\lambda}-\delta_{1}\right)^{2}} .
$$

Standard uncertainty of the standard is given in its calibration certificate. If the expanded uncertainty is $\mathrm{U}$ for a coverage probability $\mathrm{P}=95 \%$ it can be written:

$$
\mathrm{u}\left(\delta_{2}\right)=\frac{\mathrm{U}}{2} .
$$

The correction $\delta_{p c}$ due to the finite resolution of the standard display is with rectangular probability distribution. The estimate is zero and margins $\delta_{p c}^{\prime}$, being a half of the least significant digit displayd by the standard.. Based on the above information the standard uncertainty is:

$$
\mathrm{u}\left(\delta_{\mathrm{pc}}\right)=\frac{\delta_{\mathrm{pc}}{ }^{\prime}}{\sqrt{3}} .
$$

Uncertainty contributions $u_{i}(\delta)$ related to the output estimate $\delta$, are calculated by the following expression:

$$
u_{i}(\delta)=c_{i} \cdot u\left(\delta_{i}\right)
$$

where $c_{i}$ are sensitivity coefficients related to input estimate $\delta_{i}$, i.e. fractional derivatives of the model function with a respect to $\Delta_{i}$ and estimates $\delta_{i}$ of the input values: $\mathrm{c}_{1}=\frac{\partial \delta}{\partial \delta_{1}}=\frac{\partial \Delta}{\partial \Delta_{1}}=1$;

$$
\mathrm{c}_{2}=\frac{\partial \delta}{\partial \delta_{2}}=\frac{\partial \Delta}{\partial \Delta_{2}}=-1 ; \mathrm{c}_{3}=\frac{\partial \delta}{\partial \delta_{\mathrm{pc}}}=\frac{\partial \Delta}{\partial \Delta_{\mathrm{pc}}}=1
$$

and $u\left(\delta_{i}\right)$ are standard uncertainty of the input values. The standard uncertainty associated with output estimate is:

$$
u(\delta)=\sqrt{\sum_{i=1}^{3} u_{i}^{2}(\delta)}
$$

where: $\mathrm{u}_{1}(\delta)=\mathrm{u}\left(\delta_{1}\right) ; \mathrm{u}_{2}(\delta)=-\mathrm{u}\left(\delta_{2}\right)$;

$$
\mathrm{u}_{3}(\delta)=\mathrm{u}\left(\delta_{p c}\right) \text {. }
$$

The expanded measurement uncertainty $U$ is found as a product of standard uncertainty $u(\delta)$ of the output estimate and coverage factor $k$ :

$$
U=k \cdot u(\delta) \text {. }
$$

For a normal distribution of measured quantity and a coverage probability $95 \%$,

$k$ may be assumed $=2$ and formula (12) is modified:

$$
U=2 . u(\delta)
$$

\section{4) Presentation of calibrations results}

The first part of the presented results includs information about the calibrated electricity meter and conditions of calibration-TABLE1. The second part is Uncertainty budget presented in the TABLE 2 . 
TABLE I. - Measurement results for different load currents (calibration points).

\begin{tabular}{|c|c|c|c|c|}
\hline Current value & Power factor & Error value, $\%$ & $\begin{array}{c}\text { Aritmetic mean } \\
\text { of the error, } \%\end{array}$ & Uncertainty, \% \\
\hline \multirow{2}{*}{$10 \% \mathrm{I}_{\mathrm{H}}$} & 1 & $\varepsilon_{1} \ldots \varepsilon_{\lambda}$ & $\delta_{1}$ & $u\left(\delta_{1}\right)$ \\
\cline { 2 - 5 } & 0,5 lagging & $\varepsilon_{1} \ldots \varepsilon_{\lambda}$ & $\delta_{1}$ & $u\left(\delta_{1}\right)$ \\
\hline \multirow{2}{*}{$20 \% \mathrm{I}_{\mathrm{H}}$} & 1 & $\varepsilon_{1} \ldots \varepsilon_{\lambda}$ & $\delta_{1}$ & $u\left(\delta_{1}\right)$ \\
\cline { 2 - 5 } & 0,5 lagging & $\varepsilon_{1} \ldots \varepsilon_{\lambda}$ & $\delta_{1}$ & $u\left(\delta_{1}\right)$ \\
\hline \multirow{2}{*}{$50 \% \mathrm{I}_{\mathrm{H}}$} & 1 & $\varepsilon_{1} \ldots \varepsilon_{\lambda}$ & $\delta_{1}$ & $u\left(\delta_{1}\right)$ \\
\cline { 2 - 5 } & 0,5 lagging & $\varepsilon_{1} \ldots \varepsilon_{\lambda}$ & $\delta_{1}$ & $u\left(\delta_{1}\right)$ \\
\hline \multirow{2}{*}{$100 \% \mathrm{I}_{\mathrm{H}}$} & 1 & $\varepsilon_{1} \ldots \varepsilon_{\lambda}$ & $\delta_{1}$ & $u\left(\delta_{1}\right)$ \\
\cline { 2 - 5 } & 0,5 lagging & $\varepsilon_{1} \ldots \varepsilon_{\lambda}$ & $\delta_{1}$ & $u\left(\delta_{1}\right)$ \\
\hline
\end{tabular}

TABLE II. - Uncertainty budget

\begin{tabular}{|c|c|c|c|c|c|}
\hline $\begin{array}{c}\text { Quantity } \\
\Delta_{\mathrm{I}}\end{array}$ & $\begin{array}{c}\text { Estimate } \\
\delta_{\mathrm{i}}, \%\end{array}$ & $\begin{array}{c}\text { Probability } \\
\text { Distribution }\end{array}$ & $\begin{array}{c}\text { Standard } \\
\text { uncertainty } \\
\mathrm{u}\left(\delta_{\mathrm{i}}\right), \%\end{array}$ & $\begin{array}{c}\text { Sensitivity } \\
\text { Coefficient } \\
\mathrm{c}_{\mathrm{I}}\end{array}$ & $\begin{array}{c}\text { Uncertainty } \\
\text { Contribution } \\
\mathrm{u}_{\mathrm{i}}(\delta)=\mathrm{c}_{\mathrm{i}} \mathrm{u}\left(\delta_{\mathrm{i}}\right) \\
\%\end{array}$ \\
\hline $\begin{array}{c}\text { Error of the } \\
\text { measured } \\
\text { Energy }\end{array}$ & $\delta_{1}$ & Normal & $\mathrm{u}\left(\delta_{1}\right)$ & 1 & $\mathrm{u}_{1}(\delta)$ \\
\hline $\begin{array}{c}\text { Error of the } \\
\text { Standard }\end{array}$ & $\delta_{2}$ & Normal & $u\left(\delta_{2}\right)$ & -1 & $-\mathrm{u}_{2}(\delta)$ \\
\hline $\begin{array}{c}\text { Correction } \\
\text { due to the } \\
\text { display } \\
\text { resolution }\end{array}$ & 0 & Rectangular & $u\left(\delta_{3}\right)$ & 1 & $\mathrm{u}_{3}(\delta)$ \\
\hline$\Delta$ & $\Delta$ & Normal & & & $\mathrm{U}(\delta)$ \\
\hline
\end{tabular}

\section{Electrical circuits}

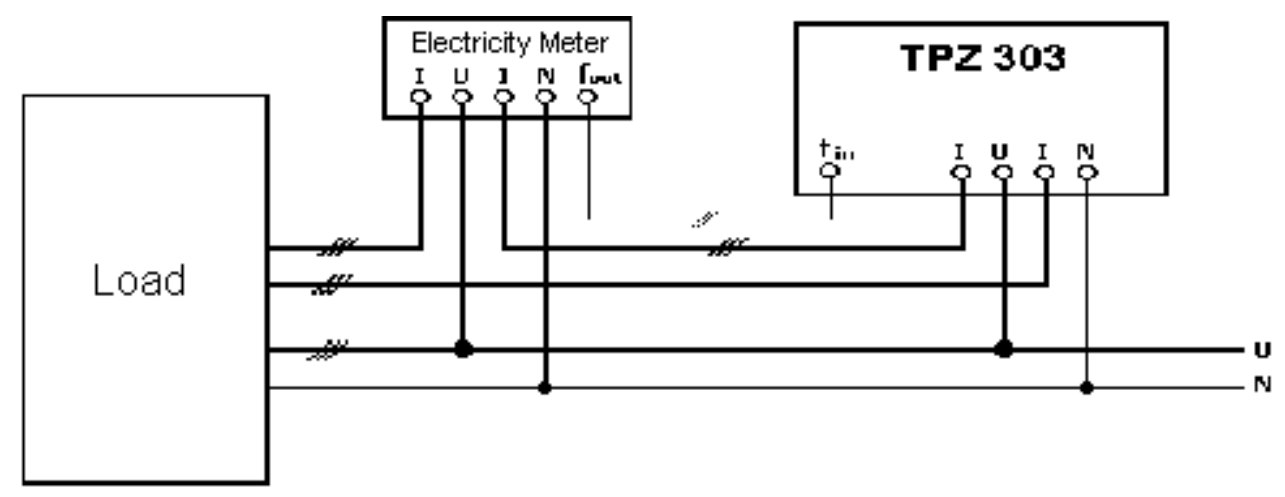

Fig. 2 - Four-Wire Energy Measurement 


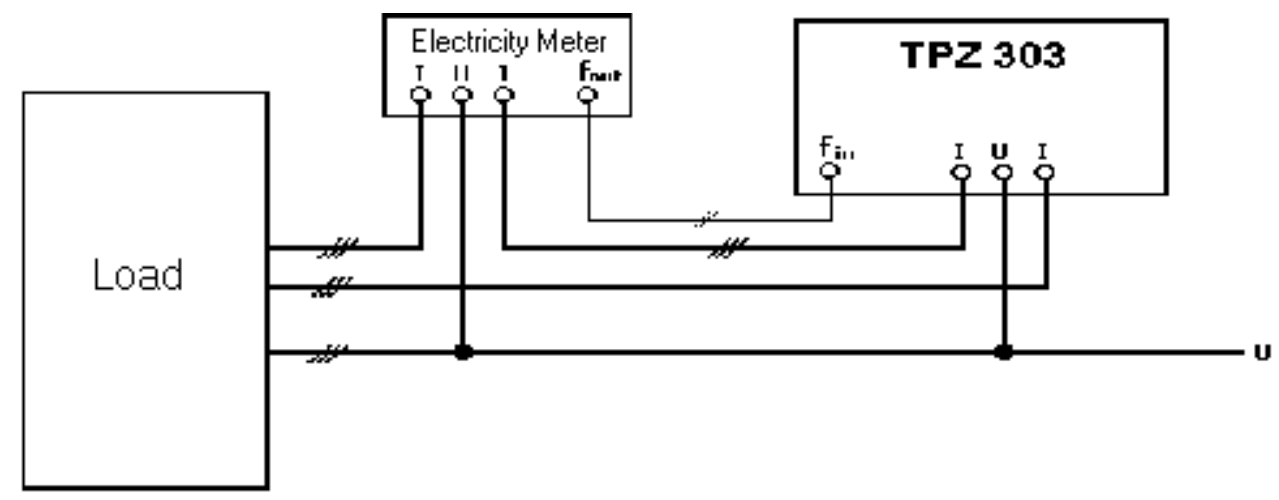

Fig.3. - Three-Wire Energy Measurement

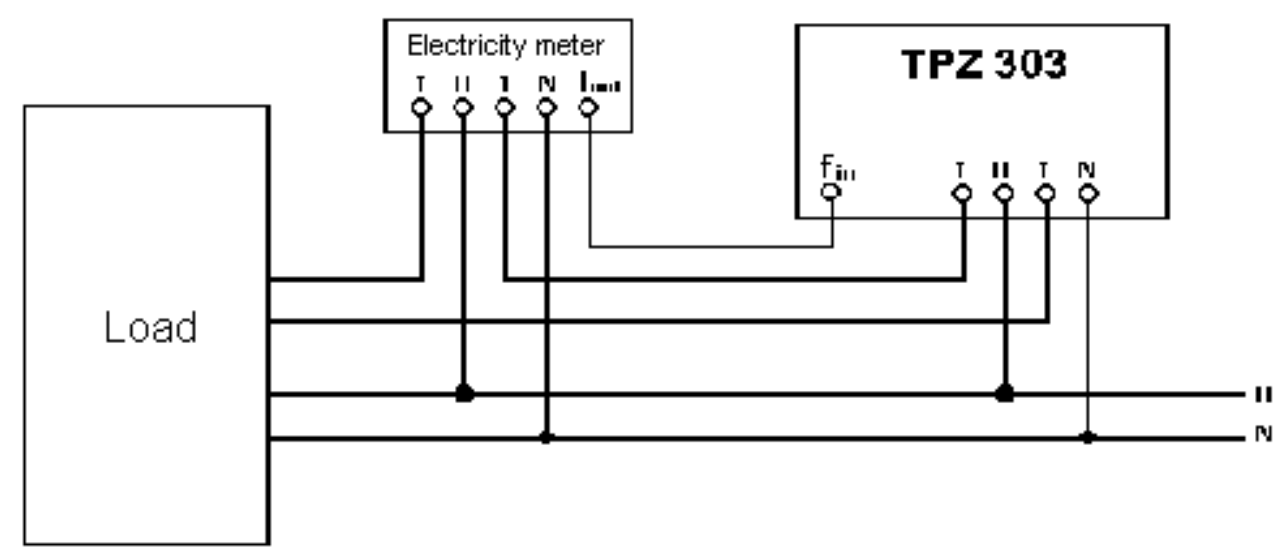

Fig. 4. - Two-Wire Energy Measurement

\section{Conclusion}

Having the information about the accuracy of both voltage and current instrument transformers and finding the uncertainty of electricity meter (according to the method just outlined), it is possible to determine the total uncertainty of energy (power) measurement in conditions of load current variations and different modes of operation. The final accuracy of energy measurement may be presented by giving the specification limits in terms of measured value.

\section{References}

[1] BSS 17371-95 "Static Electricity Meters (electronic). Technical requirements and testing methods.

[2] BSS 17397-98 "Metrology. Dictionary of the basic and comon terms in metrology"

[3] BSS ISO IEC 17025 "General requirements for competence of testing and calibration laboratories"

[4] BSS ISO 1000 "Units SI and recommendations for application of divisible and other units"

[5] BSS ISO 31-5 "Quantities and Units. Part 5: Electricity and magnetism"

[6] EA, publication EA-4/02 "Expression of the Uncertainty of Measurement and Calibration" 